Table 2. Treatment-emergent AEs through week 52

\begin{tabular}{lccc}
\hline Event, $\mathbf{n}(\%)$ & $\begin{array}{c}\text { FIL 200 } \\
(\mathbf{n}=\mathbf{4 7 5})\end{array}$ & $\begin{array}{c}\text { FIL 100 } \mathbf{~ m g} \\
\mathbf{( n = 4 8 0 )}\end{array}$ & $\begin{array}{c}\text { ADA } \\
\mathbf{( n = 3 2 5})\end{array}$ \\
\hline All AEs & $352(74.1)$ & $350(72.9)$ & $239(73.5)$ \\
Serious AEs & $35(7.4)$ & $40(8.3)$ & $22(6.8)$ \\
Infection & $206(43.4)$ & $194(40.4)$ & $129(39.7)$ \\
Serious infection & $13(2.7)$ & $13(2.7)$ & $10(3.1)$ \\
Herpes zoster & $6(1.3)$ & $4(0.8)$ & $2(0.6)$ \\
VTE & $1(0.2)$ & 0 & $1(0.3)$ \\
MACE (adjudicated) & 0 & $2(0.4)$ & $1(0.3)$ \\
Malignancy (excluding NMSC) & $2(0.4)$ & $2(0.4)$ & $2(0.6)$ \\
NMSC & $1(0.2)$ & $1(0.2)$ & 0 \\
Death & $3(0.6)$ & $1(0.2)$ & $1(0.3)$ \\
\hline
\end{tabular}

Data omitted for patients rerandomised from placebo to FIL.

ADA, adalimumab; AE, adverse event; FIL, filgotinib; MACE, major adverse cardiovascular event; NMSC, nonmelanoma skin cancer; VTE, venous thromboembolism.

Figure 1. Proportion of patients with DAS28(CRP) $<2.6$ through week 52 with nonresponder imputation

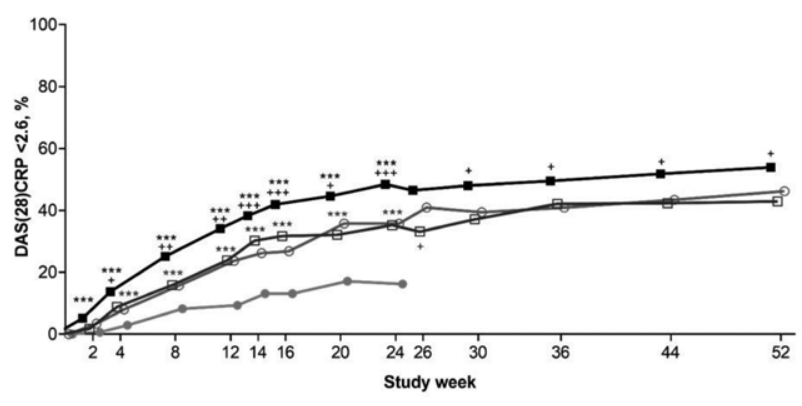

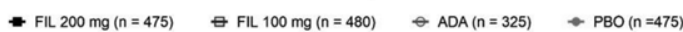

... p v v $\mathrm{PBO}<0.001$, not adjusted for multiplicity except at week $12 ;{ }^{+}$, p vs $\mathrm{ADA}<0.05,{ }^{+}$, p vs ADA $<0.01,{ }^{++}$, p vs ADA $<0.001$, not adjusted for multiplicity

ADA, adalimumab; FIL, filgotinib; PBO, placebo.

Conclusion: Through W52, both FIL 200 and $100 \mathrm{mg}$ showed sustained efficacy based on clinical and pt-reported outcomes and radiographic progression and were well tolerated in MTX-IR pts with RA, with faster onset and numerically greater efficacy for FIL 200 vs $100 \mathrm{mg}$.

Figure 2. Patients in remission at weeks 12,24 , and 52

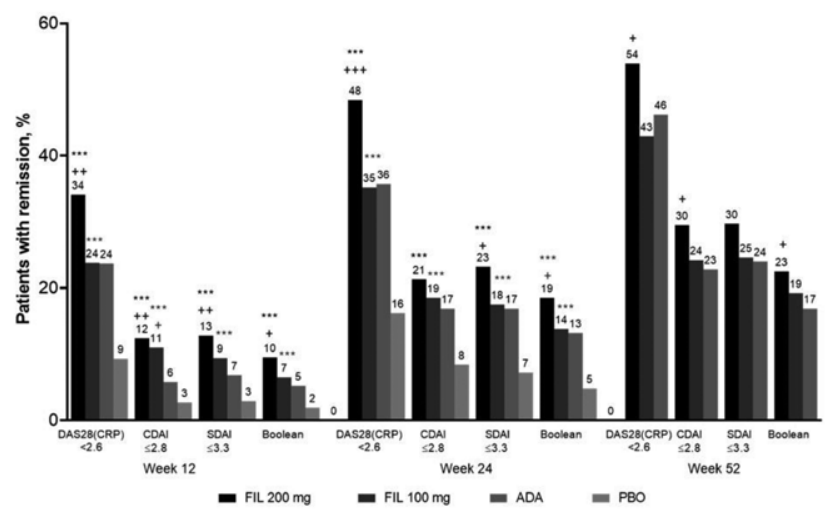

... , p vs PBO $<0.001$, not adjusted for multiplicity except DAS28(CRP) at week $12 ;{ }^{+}$, p vs ADA $<0.05 ;^{++}$, p v $A D A<0.01 ;{ }^{++}$, p v ADA $<0.001$; not adjusted for multiplicity.

$\mathrm{ADA}$, adalimumab; FIL, filgotinib; $\mathrm{PBO}$, placebo.

References:

[1] Combe et al., Ann Rheum Dis. 2019; 78 (Suppl 2):77-8.

Disclosure of Interests: Bernard Combe Grant/research support from: Novartis, Pfizer, Roche-Chugai, Consultant of: AbbVie; Gilead Sciences, Inc.; Janssen; Eli Lilly and Company; Pfizer; Roche-Chugai; Sanofi, Speakers bureau: Bristol-Myers Squibb; Gilead Sciences, Inc.; Eli Lilly and Company; Merck Sharp \& Dohme; Pfizer; Roche-Chugai; UCB, Alan Kivitz Shareholder of: AbbVie, Amgen, Gilead, GSK, Pfizer Inc, Sanofi, Consultant of: AbbVie,
Boehringer Ingelheim,,Flexion, Genzyme, Gilead, Janssen, Novartis, Pfizer Inc, Regeneron, Sanofi, SUN Pharma Advanced Research, UCB, Paid instructor for: Celgene, Genzyme, Horizon, Merck, Novartis, Pfizer, Regeneron, Sanofi, Speakers bureau: AbbVie, Celgene, Flexion, Genzyme, Horizon, Merck, Novartis, Pfizer Inc, Regeneron, Sanofi, Yoshiya Tanaka Grant/ research support from: Asahi-kasei, Astellas, Mitsubishi-Tanabe, Chugai, Takeda, Sanofi, Bristol-Myers, UCB, Daiichi-Sankyo, Eisai, Pfizer, and Ono, Consultant of: Abbvie, Astellas, Bristol-Myers Squibb, Eli Lilly, Pfizer, Speakers bureau: Daiichi-Sankyo, Astellas, Chugai, Eli Lilly, Pfizer, AbbVie, YL Biologics, Bristol-Myers, Takeda, Mitsubishi-Tanabe, Novartis, Eisai, Janssen, Sanofi, UCB, and Teijin, Désirée van der Heijde Consultant of: AbbVie, Amgen, Astellas, AstraZeneca, BMS, Boehringer Ingelheim, Celgene, Cyxone, Daiichi, Eisai, Eli-Lilly, Galapagos, Gilead Sciences, Inc., GlaxoSmith-Kline, Janssen, Merck, Novartis, Pfizer, Regeneron, Roche, Sanofi, Takeda, UCB Pharma; Director of Imaging Rheumatology BV, J-Abraham Simon-Campos: None declared, Herbert S.B. Baraf Grant/research support from: Horizon; Gilead Sciences, Inc.; Pfizer; Janssen; AbbVie, Consultant of: Horizon; Gilead Sciences, Inc.; Merck; AbbVie, Speakers bureau: Horizon, Uma Kumar: None declared, Franziska Matzkies Shareholder of: Gilead Sciences, Inc., Employee of: Gilead Sciences, Inc., Beatrix Bartok Shareholder of: Gilead Sciences Inc., Employee of: Gilead Sciences Inc., Lei Ye Shareholder of: Gilead Sciences Inc., Employee of: Gilead Sciences Inc., Ying Guo Shareholder of: Gilead Sciences, Inc., Employee of: Gilead Sciences, Inc., Chantal Tasset Shareholder of: Galapagos (share/warrant holder), Employee of: Galapagos, John Sundy Shareholder of: Gilead Sciences, Inc., Employee of: Gilead Sciences, Inc., Angelika Jahreis Shareholder of: Gilead Sciences, Inc., Employee of: Gilead Sciences, Inc., Neelufar Mozaffarian Shareholder of: Gilead, Employee of: Gilead, Robert B.M. Landewé Consultant of: AbbVie; AstraZeneca; Bristol-Myers Squibb; Eli Lilly \& Co.; Galapagos NV; Novartis; Pfizer; UCB Pharma, Sang-Cheol Bae: None declared, Edward Keystone Grant/research support from: AbbVie; Amgen; Gilead Sciences, Inc; Lilly Pharmaceuticals; Merck; Pfizer Pharmaceuticals; PuraPharm; Sanofi, Consultant of: AbbVie; Amgen; AstraZeneca Pharma; Bristol-Myers Squibb Company; Celltrion; F. Hoffman-La Roche Ltd.; Genentech, Inc; Gilead Sciences, Inc.; Janssen, Inc; Lilly Pharmaceuticals; Merck; Myriad Autoimmune; Pfizer Pharmaceuticals, Sandoz, Sanofi-Genzyme, Samsung Bioepsis., Speakers bureau: AbbVie; Amgen; Bristol-Myers Squibb; Celltrion; F. Hoffman-La Roche Ltd, Janssen, Inc; Merck; Pfizer Pharmaceuticals; Sanofi-Genzyme; UCB, Peter Nash Grant/research support from: AbbVie, Bristol-Myers Squibb, Celgene, Eli Lilly and Company, Gilead, Janssen, MSD, Novartis, Pfizer Inc, Roche, Sanofi, UCB, Consultant of: AbbVie, Bristol-Myers Squibb, Celgene, Eli Lilly, Gilead, Janssen, MSD, Novartis, Pfizer Inc, Roche, Sanofi, UCB, Speakers bureau: AbbVie, Bristol-Myers Squibb, Celgene, Eli Lilly, Gilead, Janssen, MSD, Novartis, Pfizer Inc, Roche, Sanofi, UCB DOI: 10.1136/annrheumdis-2020-eular.276

\begin{tabular}{|l|l}
\hline THU0199 & ABX464, A NOVEL DRUG IN THE FIELD OF \\
INFLAMMATION, INCREASES MIR-124 AND \\
MODULATES MACROPHAGES AND T-CELL \\
FUNCTIONS.
\end{tabular}

C. Begon-Pescia ${ }^{1}$, J. Mielle ${ }^{1}$, N. Campose ${ }^{2}$, K. Chebli $^{1}$, L. Manchon ${ }^{1}$, J. Santo ${ }^{2}$, C. Apolit², K. Martin ${ }^{2}$, L. Lapasset ${ }^{2}$, A. Vautrin ${ }^{2}$, D. Scherrer ${ }^{2}$, A. Garcel ${ }^{2}$, J. Tazi ${ }^{2}$, C. Daien ${ }^{1,3}$. ${ }^{1}$ /GMM, UMR5535, Cooperative Lab, Montpellier, France ${ }^{2}$ Abivax Therapeutics, Cooperative Lab, Montpellier, France; ${ }^{3}$ Hospital and University of Montpellier, Montpellier, France

Background: $A B X 464$ is a small oral molecule with a novel mode of action. It binds the Cap Binding Complex, involved in the biogenesis of RNAs and predominantly upregulates the expression of a microRNA miR-124 in PBMCs and T cells (1). miR-124 has been widely described for its anti-inflammatory properties, with many confirmed targets i.e. monocyte chemoattractant protein 1 (MCP-1, CXCL-1, SERPIN-E1, STAT-3, IL-6 receptor. It post-transcriptionally regulates the expression of MCP-1 in rheumatoid arthritis (RA) synoviocytes and decreases their proliferation (2). While miR-124 is decreased in synoviocytes of RA patients, its injection in joint improved arthritis in rats (3). miR-124 expression in macrophages leads to the induction and maintenance of anti-inflammatory M2 phenotype (4). Its effect in T cells remains controversial.

Objectives: (i) To assess the effect of ABX464 on miR-124 expression in vitro in macrophages and in vivo in patients; (ii) to assess the effect of $A B X 464$ 
on arthritis in mice and (iii) to decipher the effect of ABX464 on human macrophages and T cells.

Methods: miR-124 was measured in human monocyte-derived macrophages (huMDM) treated with ABX464 for 4 days and in patients with ulcerative colitis included in a phase Ila RCT in blood and rectal biopsies at day 56 by TaqMan qPCR. Collagen-induced arthritis (CIA) was induced using usual protocol and ABX464 was given by gavage 2 weeks at $40 \mathrm{mg} / \mathrm{kg}$ after the $2^{\text {nd }}$ injection of collagen and Freund adjuvant. HuMDM were exposed to $5 \mu \mathrm{M}$ of ABX464 or DMSO (control) for 4 days, during a M1-polarization. Cytokines and chemokines were assessed in supernatants using both Proteome Profiler Array and Luminex. PBMCs were exposed to ABX464 (5 $\mu \mathrm{M})$ for 6 days. Th1 (IFN-g+), Th17 (CCR6+IL-17+), Th2 (CRTH2+ IL-4+) and Tregs (CD25+CD125-/loFoxP3+) were assessed by flow cytometry. IL-6 receptor was assessed in CD4+ supernatant using ELISA.

Results: ABX464 increased miR-124 in vitro by 3.41 folds in huMDM ( $p=0.001$ ) compared to DMSO. The phase Ila RCT conducted in 32 patients with moderate to severe active ulcerative colitis showed a good safety profile and significant clinical efficacy. A strong increase of miR-124 was observed both in blood and rectal biopsies of patients treated with ABX464 (637 and 7.69 folds respectively, compared to placebo, $\mathrm{p}<0.05)$. The use of $A B X 464$ drastically decreased the incidence of arthritis from 52\% (15/ 29 mice) to 10\% (3/30 mice) in a CIA model. Macrophages treated with ABX464 produced significantly less MCP-1 (median decrease $-67 \%, \mathrm{p}=0.004)$, CXCL-1 (-18\%, $\mathrm{p}=0.004)$ and SERPIN-E1 $(-53 \%, p=0.004)$, as confirmed by the two technics $(n=9)$. ABX464 significantly decreased Th17 (-56\%, $p=0.02)$, while increasing Th2 (+21\%, $p=0.01)$. IL-6 soluble receptor was significantly decreased in supernatant of PBMCs treated with ABX464 (-43\%, p=0.04).

Conclusion: We demonstrated that $\mathrm{ABX} 464$ increases miR-124 both in vitro and in ulcerative colitis patients. In vitro, $\mathrm{ABX} 464$ decreased the expression of miR-124 target genes, that is MCP-1, CXCL-1, SERPIN-E1 in macrophages and decreases the number of Th17 as well as IL-6 soluble receptor in CD4+ T cells. A phase Ila RCT is currently ongoing in patients with rheumatoid arthritis and inadequate response to methotrexate and/or TNF-inhibitors $(n=60)$. Results are expected during 2020 summer.

References:

[1] Vautrin A et al. Sci Rep. 2019;9:792

[2] Nakamachi Y et al. Arthritis Rheum 2009; 60:1294-304

[3] Nakamachi $Y$ et al. Ann Rheum Dis 2016; 75:601-8

[4] Veremeyko T et al. PLoS ONE 2013; 8:e81774

Disclosure of Interests: Christina BEGON-PESCIA: None declared, Julie Mielle: None declared, Noélie Campose Employee of: ABIVAX, Karim Chebli Consultant of: ABIVAX, Laurent Manchon: None declared, Julien Santo Employee of: ABIVAX, Cécile Apolit Employee of: ABIVAX, Kévin Martin Grant/ research support from: ABIVAX, Laure Lapasset Employee of: ABIVAX, Audrey Vautrin Employee of: ABIVAX, Didier Scherrer Employee of: ABIVAX, Aude Garcel Employee of: ABIVAX, Jamal Tazi Shareholder of: ABIVAX, Grant/ research support from: $A B I V A X$, Consultant of: ABIVAX, Employee of: ABIVAX, Paid instructor for: ABIVAX, Speakers bureau: ABIVAX, Claire DAIEN Grant/ research support from: from Pfizer, Abbvie, Roche-Chugaï, Novartis, Abivax, Sandoz, Consultant of: Abbvie, Abivax, BMS, MSD, Roche-Chugaï, Lilly, Novartis, Speakers bureau: Abbvie, Abivax, BMS, MSD, Roche-Chugaï, Lilly, Novartis

DOI: 10.1136/annrheumdis-2020-eular.4959

\section{THU0200 FIRST LINE THERAPY: DATA OF THE TARDIS-RA REGISTRY, A NATIONWIDE BELGIAN BIOLOGIC REGISTRY}

D. De Cock ${ }^{* 1}$, P. Durez ${ }^{2,3}$, D. Elewaut ${ }^{4,5}$, B. Lauwerys ${ }^{2,3}$, R. Westhovens ${ }^{1,6}$, P. Verschueren ${ }^{1,6} .{ }^{1}$ Skeletal Biology and Engineering Research Centre, KU Leuven, Leuven, Belgium; ${ }^{2}$ Pôle de Pathologies Rhumatismales Inflammatoires et Systémiques, Institut de Recherche Expérimentale et Clinique, Université Catholique de Louvain, Brussel, Belgium; ${ }^{3}$ Department of Rheumatology, Cliniques Universitaires Saint-Luc, Brussel, Belgium; ${ }^{4}$ Department of Rheumatology - MRB2, Ghent University Hospital, Ghent,
Belgium; ${ }^{5}$ VIB Center for Inflammation Research, Ghent University, Ghent, Belgium; ${ }^{6}$ Rheumatology, University Hospitals Leuven, Leuven, Belgium

Background: The Tool for Administrative Reimbursement Drug Information Sharing (TARDIS) is an electronic platform combining data collection from all Belgian patients with Rheumatoid Arthritis (RA) on advanced therapy, together with a drug reimbursement request. Therapy choice after initial 2 classical synthetic DMARD failure is left to the treating rheumatologist in Belgium.

Objectives: To investigate first-line therapy choices for tumor necrosis factor inhibitor (TNFi) biologic (b) DMARDs, non-TNFi bDMARDs or targeted synthetic (ts) DMARDs via patient characteristics and initial treatment response in the TARDIS-RA registry.

Methods: All Belgian rheumatologist inserted patient data online when prescribing a b/tsDMARD. When data was entered for the first time, previous and current use of DMARD therapies was registered. Every next bDMARD or tsDMARD initiation, prolongation and discontinuation was registered electronically. First prolongation is 6 months for bDMARDs and 12 weeks for tsDMARDs, and yearly thereafter. Patients were selected for this analysis if they started a TNFi, non-TNFi or tsDMARD therapy between Jan 2018 and Jan 2019. Rituximab was excluded. Baseline characteristics of bionaive patients per therapy were compared with Mann-Whitney $\mathrm{U}$ or $\mathrm{Chi}^{2}$ tests were appropriate. Regression analyses, adjusted for age, DAS28 baseline and disease duration, evaluated DAS28 change, remission (DAS28<2.6) and low disease activity (LDA, DAS28<3.2) between b/tsDMARDs at first TARDIS follow-up.

Results: In 2018, 1263 bionaive RA patients were included. Table 1 describes this population. Time until $1^{\text {st }}$ follow-up differed between groups with 183 (181184) days for bDMARD versus 84 (84-84) days for tsDMARD patients. Lineair regression showed an effect of therapy type on DAS28 change in bionaive patients $(p=0.017)$. Logistic regression showed no difference per therapy for remission $(p=0.090)$ nor low disease activity $(p=0.123)$. Proportions of therapy prolongations at $1^{\text {st }}$ follow up visit did not differ per therapy type.

Table 1. Baseline characteristics and treatment response of first-line TNFi, Non-TNFi or tsDMARDs

\begin{tabular}{lllll}
\hline & TNFi & Non-TNFi & tsDMARD & p-value \\
\hline Number patients & $696(57 \%)$ & $293(25 \%)$ & $215(18 \%)$ & \\
Age (years) & $55,(45-64)$ & $58,(51-68)$ & $58,(49-66)$ & $<0.001$ \\
Disease duration (years) & $3,(1-7)$ & $3,(1-9)$ & $5,(2-13)$ & $<0.001$ \\
DAS28 Baseline & $4.8,(4.3-5.5)$ & $5.1,(4.4-5.7)$ & $4.7,(4.2-5.4)$ & 0.010 \\
DAS28 Change & $2.2(1.0-3.0)$ & $2.2(1.1-3.2)$ & $1.9(0.9-2.7)$ & 0.014 \\
Remission & $296(50 \%)$ & $123(49 \%)$ & $78(42 \%)$ & 0.143 \\
LDA & $377(64 \%)$ & $153(61 \%)$ & $105(56 \%)$ & 0.196 \\
Prolongation therapy & $492(82 \%)$ & $219(87 \%)$ & $161(86 \%)$ & 0.158
\end{tabular}

Number given are median, (IQR) or number (proportion). TNFi = tumour necrosis factor inhibitor, ts= targeted synthetic, DAS = disease activity score, DAS28 change = DAS28 at 1 st follow up visit minus DAS28 at baseline, remission $=$ DAS28<2.6), LDA = low disease activity DAS28<3.2), Prolongation = therapy was continued at 1st follow-up visit. Mann-Whitney $U$ or Chi square tests were used where appropriate.

Conclusion: Initial therapy choices are partially driven by patient profile, although other factors such as patient preferences could not be verified. DAS28 change for tsDMARDs seemed less important versus bDMARDs, but can possibly be attributed to the preset evaluation moment being sooner for tsDMARDs versus bDMARDs aside of patient profile differences in age and disease duration. In contrast, proportion of remission, low disease activity and therapy prolongation did not differ by therapy.

Disclosure of Interests: Diederik De Cock: None declared, Patrick Durez Speakers bureau: AbbVie, Bristol-Myers Squibb, Celltrion, Eli Lilly, Pfizer Sanofi, Dirk Elewaut: None declared, Bernard Lauwerys: None declared, Rene Westhovens Grant/research support from: Celltrion Inc, Galapagos, Gilead, Consultant of: Celltrion Inc, Galapagos, Gilead, Speakers bureau: Celltrion Inc, Galapagos, Gilead, Patrick Verschueren Grant/research support from: Pfizer unrestricted chair of early RA research, Speakers bureau: various companies

DOI: 10.1136/annrheumdis-2020-eular.6192 